\title{
Health Professionals Facing Burnout: What Do We Know about Nursing Managers?
}

\author{
Jean-Luc Heeb ${ }^{1}$ and Véronique Haberey-Knuessi ${ }^{2}$ \\ ${ }^{1}$ Haute Ecole Fribourgeoise de Travail Social, University of Applied Sciences of Western Switzerland, Rue Jean-Prouvé 10, \\ 1762 Givisiez, Switzerland \\ ${ }^{2}$ Haute Ecole de Santé ARC, University of Applied Sciences of Western Switzerland, Espace de l'Europe 11, \\ 2000 Neuchâtel, Switzerland \\ Correspondence should be addressed to Jean-Luc Heeb; jean-luc.heeb@hef-ts.ch
}

Received 9 January 2014; Revised 5 March 2014; Accepted 10 March 2014; Published 3 April 2014

Academic Editor: Maria Helena Palucci Marziale

Copyright (C) 2014 J.-L. Heeb and V. Haberey-Knuessi. This is an open access article distributed under the Creative Commons Attribution License, which permits unrestricted use, distribution, and reproduction in any medium, provided the original work is properly cited.

\begin{abstract}
Objective. To address the degree of burnout in nursing managers in hospitals of Western Switzerland, including comparison with medical managers, and its relationship with personal, work-related, and organizational characteristics. Methods. Statistical analysis of the scores of the Maslach Burnout Inventory-Human Services Survey from 257 nursing managers who answered a standardized electronic questionnaire. Results. Nursing managers showed a low degree of burnout, which was similar to that of medical managers. Most of them had a low level of emotional exhaustion and a low level of depersonalization, while personal accomplishment was contrasted. Only $2.3 \%$ had a high degree of burnout. These findings challenge the hypothesis of high stress being associated with high burnout, as nursing managers can be supposed to have a highly demanding job due to their intermediary position within the hospital hierarchy. Variations of burnout by personal, work-related, and organizational characteristics mainly concerned emotional exhaustion. Conclusion. Though nursing managers face a highly demanding job, they may benefit from resources (including coping strategies and empowerment) which help counterbalance job stress. Unequal distribution of resources may play a central role when facing burnout.
\end{abstract}

\section{Introduction}

Growing evidence has accumulated in the past decades that burnout is a widespread phenomenon among health professionals with adverse consequences on individual health, organizational functioning, quality of care, and patient outcome. Consistent with the hypothesis that high stress results in an increased risk of burnout, research in the field of nursing concentrated on professionals working in demanding settings such as oncology, intensive care, and palliative care. Nursing managers, however, have received very little attention to date, though they accomplish a highly demanding job with both management tasks and work with patients. Furthermore, due to their intermediary position within the hospital hierarchy, they are involved in ongoing hospital reforms, which have been recognized to accentuate the risk of burnout. Thus, scarce evidence and the changing context of the health system in Western countries suggest examining the degree of burnout among nursing managers.

Since Freudenberger's [1] seminal work among health professionals in the $70 \mathrm{~s}$, there has been a continuing and growing interest in burnout in the fields of both research and public opinion. Burnout was described as a syndrome referring to mental and physical exhaustion that is rooted in the professional career. Still according to Freudenberger, burnout is likely to appear when professionals are emotionally highly implicated with their patients but the results they expect do not realize, thus curtailing their motivation and causing responses like tiredness, sleepiness, failing to cope, angriness, or cynicism. This view of burnout is mainly individually centred, as it emphasizes the professionals' behaviour and emotions, but it also points to the discrepancy between an idealized self and reality. Therefore, professionals with high expectancies are most at risk to face a "state of fatigue or 
frustration brought about by a devotion to a cause, a way of life, or a relationship that failed to produce the expected reward" [2, page 13].

While personal investment is central to understanding burnout, conditions of work should also be included [3]. As a result, situational stressors may play a central role when they curtail the sense that the professionals attribute to their work [4]. Recent changes in the health systems may interfere with the meaning and the goals that the health professionals attribute to their work. As in other countries, Swiss public organizations are faced with structural and managerial changes, mainly the introduction of the principles of the new public management, meaning the application of market-oriented management to the public sector which is supposed to increase the efficiency and customer orientation [5]. However, such policies have been shown to be associated with an increased workload and a loss of meaning in the professionals' work. Consequences include intensification of work [6], especially administration [7], diminishing nurse/patient ratio [8], and cross-training of personnel [9]. At the same time, professionals are challenged by demographic changes resulting in higher rates of older patients with multiple pathologies $[10,11]$.

At the health professionals level burnout is associated with a variety of adverse outcomes ranging from irritability, sleepiness, and depression to self-depreciation or addictive behaviours $[12,13]$ which may affect the relationship with the patient and result in decreased performance, turnover, and absenteeism at the organizational level [14].

Burnout is most often looked at across the three dimensions of emotional exhaustion, depersonalization, and reduced personal accomplishment [15]. Emotional exhaustion refers to a lack of energy and interest in one's work due to the experience of drained emotional resources. Depersonalization or cynicism manifests in impassive attitudes and thoughts and acts as a protection from exhaustion by making a person distance oneself from others. Finally, a lack of personal accomplishment or self-efficacy reflects feelings of diminished efficacy, competence, and achievement at work. A high level of emotional exhaustion and depersonalization coupled with a reduced sense of personal accomplishment is characteristic of professionals with a high degree of burnout.

To date, studies on burnout among nurses have mainly concentrated on nursing specialities which have been considered to bear a high risk, such as oncology, intensive care, or palliative care [16]. While increased burnout in these specialities may be due to demanding emotional investment with the patients, nursing managers are also faced with a variety of relational tasks including motivation, organization, and conflict resolution with their team to achieve the management policy of the hospital, all in addition to their work with the patient. Indeed, the intermediary position of managers within the hospital hierarchy can be supposed to be a risk factor as hospital restructuring has been shown to increase the degree of burnout [17]. Based on the common view that a highly stressful work environment results in a high degree of burnout [18], nursing managers could be expected to be particularly vulnerable to burnout. This view, however, needs to be questioned in the light of empirical research.
Though health professionals are considered to present a high risk of burnout due to their emotionally demanding job, several studies reported low degrees of burnout among nurses $[19,20]$. More specifically, there is some evidence that burnout may be lower among nurses belonging to specialities perceived as very stressful than among those working in low-stress settings [21, 22]. Possible explanations for the moderate incidence of burnout may be seen in effective coping strategies [23], including empowerment [24, 25].

A central question therefore is to evaluate the degree of burnout among nursing managers: how do high job demands which are considered as risks factors and possible resources used as protective factors combine? Is burnout among nursing managers similar to nurses without a management function, is it higher, or is it lower? Despite the wide literature about burnout among health professions, studies examining nursing managers are very scarce, with a North American study suggesting a rather low degree of burnout [19]. Thus, the present study aims to contribute to filling this gap by examining the prevalence of burnout and its relationship to personal, work-related, and organizational characteristics in a sample of nursing managers from five Swiss hospitals.

\section{Methods}

2.1. Data. Data came from a cross-sectional survey about mental health and job satisfaction among hospital managers in Western Switzerland. The five surveyed hospitals include a university hospital (more than 1000 beds), two regional hospitals (from 300 to 1000), and two local hospitals (less than 300). Data were collected in 2011/2012 anonymously and by means of a standardized electronic questionnaire. It was addressed to all nurses, physicians, and administrative, financial, and technical employees with a manager status. To increase participation the survey was announced by using the internal communication of the hospitals and electronically. In each hospital local referents motivated the managers to participate. A total of 1333 managers were contacted, of whom 942 participated in the survey (nursing managers: 317, medical managers: 226, and other managers: 399). An overall response rate of $70.7 \%$ was achieved. Burnout was measured by two different instruments among the health managers and the other managers [15]. Thus, in addition to the subsample of nurses, data from physicians were used to provide comparisons. Due to incomplete data 94 respondents were excluded from the health manager subsample. The final sample consists of 449 nursing managers (257) and medical managers (192).

2.2. Instruments. Burnout among nurses and physicians was assessed by the Maslach Burnout Inventory-Human Services Survey (MBI-HSS), a 22-item questionnaire which reflects the dimensions of emotional exhaustion (9 items), depersonalization (5), and lack of personal accomplishment (8). For each item respondents had to indicate the frequency of the job-related feeling described by the item on a 7-point scale ranging from 0 (never) to 6 (every day). To ensure comparison with previous research a high degree of burnout, 
TABLE 1: Mean scores and categorization of burnout according to the MBI-HSS subscales among nursing managers (medical managers).

\begin{tabular}{lcccc}
\hline Subscale & Mean score [S.D.] & Low level & Average level & High level \\
\hline Emotional exhaustion & $16.9[7.1]$ & $61.1 \%$ & $28.0 \%$ & $(32.8 \%)$ \\
& $(17.1[8.0])$ & $(54.7 \%)$ & $53.9 \%$ & $(12.5 \%)$ \\
Depersonalization & $5.4[4.2]$ & $(57.3 \%)$ & $(23.4 \%)$ & $16.7 \%$ \\
& $(5.4[4.3])$ & $35.8 \%$ & $35.8 \%$ & $(19.3 \%)$ \\
Personal accomplishment & $35.6[6.9]$ & $(29.7 \%)$ & $(32.3 \%)$ & $(38.0 \%)$ \\
\hline
\end{tabular}

Data of medical managers are indicated in parenthesis.

that is, a high level of emotional exhaustion (score of 27 or higher) and depersonalization (10 or higher) and a low level of personal accomplishment (33 or lower), was defined according to a normative sample of North American nurses and physicians [15].

Personal, work-related, and organizational characteristics were collected in order to address variations in the scores of burnout. Core characteristics include sex, age, length of managerial experience, overtime hours, work schedule, size of the team the manager is responsible for, congruence of personal and organizational values, congruence between personal skills and job requirements, and conflicts within the team. Further characteristics considered were education, household structure, degree of activity, length of overall professional experience, and type of hospital (university, regional, or local).

2.3. Statistical Analysis. Analysis focused on nursing managers and was carried out by SPSS 19.0 [26]. Descriptive statistics of the sample characteristics and the MBI-HSS scores are provided. To address variations in the original scores, multivariate linear regression models were computed. Regression analysis concentrates on nursing managers, while descriptive findings include comparison with medical managers.

\section{Results}

3.1. Sample Description. The mean age of the surveyed nursing managers was 46.7 years; $58.0 \%$ of them were women and they most often lived with a partner and children $(56.4 \%)$ or alone with a partner $(23.3 \%)$. They had mainly achieved higher professional or university education (91.5\%) and showed longer professional experience (up to 5 years: $8.2 \%$, from 6 to 10 years: $10.9 \%$, from 11 to 15 years: $17.1 \%$, and 16 years or more: $63.8 \%$ ), including a managerial function (up to 5 years: $30.4 \%$, from 6 to 10 years: $19.5 \%$, from 11 to 15 years: $25.3 \%$, and 16 years or more: $24.9 \%$ ). The managers were usually responsible for a medium-sized team (up to 10 persons: $13.7 \%$, from 11 to $20: 16.3 \%$, from 21 to $50: 42.8 \%$, and 51 or more: $27.2 \%)$. Their degree of activity was rather high (less than 70\%: $2.3 \%$, from $70 \%$ to less than $90 \%: 12.5 \%$, and $90 \%$ or more: $85.2 \%)$. Work schedules were mostly described as regular (79.2\%) and overtime hours, though frequent, were not excessive in number (none: $1.6 \%$, from 1 to 10 hours per month: $57.2 \%$, from 11 to 20 hours: $29.6 \%$, and 21 hours or more: $11.7 \%)$. Most of the nursing managers worked either sometimes (35.5\%) or often (42.2\%) with patients. 58.8\% were employed in a university hospital, $31.9 \%$ in a regional hospital, and $9.3 \%$ in a local hospital.

3.2. Burnout by Personal, Work-Related, and Organizational Characteristics. Variations of the mean scores of the MBIHSS subscales by personal and work-related characteristics and variations of the shares of respondents with a high level of emotional exhaustion, a high level of depersonalization, and a low level of personal accomplishment are shown in Table 2. Overall, the variations of the mean scores by the characteristics mirror those of the shares. Most of the variations regard emotional exhaustion with pronounced differences related to work schedules, team size, the congruence of personal and organizational values, and conflicts within the team. Sex and length of managerial experience are associated with depersonalization and overtime with personal accomplishment.

3.3. MBI-HSS. Table 1 summarizes the descriptive findings of the MBI-HSS subscales including nursing and medical managers. The mean score of personal accomplishment was significantly lower among nurses than physicians (difference $=$ -1.48 , S.D. $=0.66, \mathrm{df}=447$, and $P=0.023$ ), while no significant difference regarding emotional exhaustion (difference $=-0.17$, S.D. $=0.71, \mathrm{df}=447$, and $P=0.808$ ) and depersonalization (difference $=0.02$, S.D. $=0.41, \mathrm{df}=447$, and $P=0.968$ ) was found. Compared with the categorization based on the normative data [15], mean scores of emotional exhaustion were low and those of personal accomplishment average while the mean scores of depersonalization are situated at the threshold between the low and average. Consistent with the mean scores, a small share of respondents had a high level of emotional exhaustion or depersonalization, with a low level being most frequent, and the shares of respondents with a low, average, or high level of personal accomplishment were rather similar.

The simultaneous occurrence of high levels of emotional exhaustion and depersonalization with a low level of personal accomplishment, that is, a high degree of burnout, concerned only a few nursing managers (2.3\%; medical managers: $3.1 \%$ ). The opposite configuration-high personal accomplishment coupled with low emotional exhaustion and depersonalization-was more frequent $(12.3 \% ; 14.6 \%)$.

3.4. Regression Analysis. Table 3 contains the results of the linear regression analysis of the scores of the MBI-HSS 
TABLE 2: Mean scores and prevalence of burnout according to the MBI-HSS subscales among nursing managers.

\begin{tabular}{|c|c|c|c|c|c|c|}
\hline \multirow{3}{*}{$\overline{\text { Sex }}$} & \multicolumn{3}{|c|}{ Mean scores [S.D.] } & \multicolumn{3}{|c|}{ Shares } \\
\hline & \multirow[t]{2}{*}{$\mathrm{EE}$} & \multirow[t]{2}{*}{ DP } & \multirow[t]{2}{*}{ PA } & \multirow[t]{2}{*}{ High EE } & \multirow[t]{2}{*}{ High DP } & \multirow[t]{2}{*}{ Low PA } \\
\hline & & & & & & \\
\hline Men & $17.2[6.8]$ & $6.9(4.2)$ & $35.7(6.9)$ & $10.2 \%$ & $25.9 \%$ & $36.1 \%$ \\
\hline Women & $16.7[7.3]$ & $4.3(3.9)$ & $35.6(6.9)$ & $11.4 \%$ & $10.1 \%$ & $35.6 \%$ \\
\hline \multicolumn{7}{|l|}{ Age } \\
\hline Up to 40 years & $17.5[7.1]$ & $5.4(4.3)$ & $35.2(7.1)$ & $13.0 \%$ & $17.1 \%$ & $38.9 \%$ \\
\hline 41 years or more & $15.3[6.8]$ & $5.4(4.0)$ & $36.9(6.1)$ & $4.7 \%$ & $15.6 \%$ & $26.6 \%$ \\
\hline \multicolumn{7}{|l|}{ Managerial experience } \\
\hline Up to 10 years & $17.0[7.1]$ & $6.0(4.2)$ & $36.1(6.4)$ & $11.7 \%$ & $21.9 \%$ & $33.6 \%$ \\
\hline 11 years or more & $16.8[7.1]$ & $4.9(4.2)$ & $35.1(7.3)$ & $10.1 \%$ & $11.6 \%$ & $38.0 \%$ \\
\hline \multicolumn{7}{|l|}{ Overtime } \\
\hline Up to 20 hours/month & $16.8[7.1]$ & $5.5(4.3)$ & $35.2(7.0)$ & $6.7 \%$ & $16.7 \%$ & $20.0 \%$ \\
\hline 21 hours/month or more & $17.6[7.1]$ & $5.2(4.2)$ & $38.6(7.3)$ & $11.5 \%$ & $16.7 \%$ & $37.9 \%$ \\
\hline \multicolumn{7}{|l|}{ Work schedule } \\
\hline Irregular & $17.2[7.1]$ & $5.4(4.2)$ & $35.7(6.9)$ & $11.7 \%$ & $15.9 \%$ & $35.1 \%$ \\
\hline Regular & $14.0[6.8]$ & $5.6(4.5)$ & $34.6(7.2)$ & $0.0 \%$ & $27.8 \%$ & $44.4 \%$ \\
\hline \multicolumn{7}{|l|}{ Team size } \\
\hline Up to 5 persons & $21.3[6.5]$ & $6.3(3.9)$ & $33.9(5.6)$ & $18.2 \%$ & $18.2 \%$ & $45.5 \%$ \\
\hline 6 persons or more & $16.5[7.0]$ & $5.3(4.2)$ & $35.8(7.0)$ & $10.2 \%$ & $16.6 \%$ & $34.9 \%$ \\
\hline \multicolumn{7}{|c|}{ Personal/organizational values fit } \\
\hline Yes & $15.7[6.8]$ & $5.3(4.3)$ & $36.4(5.8)$ & $9.0 \%$ & $16.9 \%$ & $35.0 \%$ \\
\hline Partly or no & $20.0[7.4]$ & $6.0(4.1)$ & $35.6(7.1)$ & $17.2 \%$ & $19.0 \%$ & $34.5 \%$ \\
\hline \multicolumn{7}{|l|}{ Skills/demand fit } \\
\hline High & $16.2[7.1]$ & $5.3(4.3)$ & $36.2(7.1)$ & $9.0 \%$ & $15.7 \%$ & $32.5 \%$ \\
\hline Medium or low & $18.9[7.2]$ & $5.9(4.2)$ & $34.7(7.0)$ & $17.5 \%$ & $22.8 \%$ & $42.1 \%$ \\
\hline \multicolumn{7}{|l|}{ Team conflicts } \\
\hline Frequent & $18.3[7.5]$ & $6.2(4.5)$ & $35.8(7.0)$ & $20.6 \%$ & $20.6 \%$ & $30.2 \%$ \\
\hline Seldom or none & $16.3[7.1]$ & $5.1(4.2)$ & $35.8(6.8)$ & $7.5 \%$ & $16.3 \%$ & $36.9 \%$ \\
\hline
\end{tabular}

EE: emotional exhaustion, DP: depersonalization, and PA: personal accomplishment.

TABLE 3: Linear regression model of the MBI-HSS subscales among nursing managers.

\begin{tabular}{|c|c|c|c|c|c|c|c|c|c|}
\hline & \multicolumn{3}{|c|}{$\mathrm{EE}$} & \multicolumn{3}{|c|}{ DP } & \multicolumn{3}{|c|}{ PA } \\
\hline & $\begin{array}{l}\text { Unstandardized } \\
\text { beta coefficient }\end{array}$ & $t$ & $P$ value & $\begin{array}{l}\text { Unstandardized } \\
\text { beta coefficient }\end{array}$ & $t$ & $P$ value & $\begin{array}{l}\text { Unstandardized } \\
\text { beta coefficient }\end{array}$ & $t$ & $P$ value \\
\hline Constant & 22.24 & 15.42 & 0.000 & 8.77 & 10.12 & 0.000 & 34.89 & 23.30 & 0.000 \\
\hline Men (women) & 0.74 & 0.87 & 0.384 & 2.81 & 5.54 & 0.000 & 0.11 & 0.13 & 0.896 \\
\hline Age $\leq 40$ years ( $>40$ years $)$ & 2.66 & 2.36 & 0.019 & 1.01 & 1.49 & 0.138 & 1.49 & 1.27 & 0.205 \\
\hline $\begin{array}{l}\text { Managerial experience } \leq 10 \text { years } \\
\text { ( }>10 \text { years) }\end{array}$ & 1.35 & 1.36 & 0.174 & 1.73 & 2.90 & 0.004 & 0.36 & 0.35 & 0.727 \\
\hline $\begin{array}{l}\text { Overtime } \leq 20 \text { hours per month } \\
(>20 \text { hours })\end{array}$ & -1.39 & -1.04 & 0.300 & -0.38 & -0.47 & 0.640 & 3.18 & 2.29 & 0.023 \\
\hline Irregular work schedule (regular) & 4.54 & 2.72 & 0.007 & 0.03 & 0.03 & 0.973 & -2.22 & -1.28 & 0.201 \\
\hline Team size $\leq 5$ persons ( $>5$ persons) & 5.14 & 3.39 & 0.001 & 1.06 & 1.16 & 0.246 & -1.16 & -0.73 & 0.463 \\
\hline $\begin{array}{l}\text { Personal/organizational values fit: } \\
\text { yes (partly or no) }\end{array}$ & -3.79 & -3.64 & 0.000 & -0.78 & -1.24 & 0.216 & -0.91 & -0.84 & 0.402 \\
\hline $\begin{array}{l}\text { High skills/demand fit (medium or } \\
\text { low) }\end{array}$ & -2.05 & -1.98 & 0.049 & -0.41 & -0.66 & 0.510 & 1.62 & 1.50 & 0.135 \\
\hline $\begin{array}{l}\text { Frequent team conflicts (seldom or } \\
\text { none) }\end{array}$ & 1.99 & 2.01 & 0.046 & 0.88 & 1.48 & 0.139 & -0.13 & -0.13 & 0.900 \\
\hline
\end{tabular}

EE: emotional exhaustion, DP: depersonalization, and PA: personal accomplishment.

Reference groups are indicated in parentheses. 
subscales. Of the total variance of the subscale scores, the model explained $16.9 \%$ for emotional exhaustion, $14.9 \%$ for depersonalization, and 5.4\% for personal accomplishment. The regression analysis confirms the descriptive findings of Table 2. Increased scores of emotional exhaustion are related to small team size, irregular work schedule, values discrepancy, and, to a minor extent, to young age, perceived lack of fit between personal skills and job demand, or frequent conflicts within the team. Scores of depersonalization were significantly lower among men than women and among managers with longer experience. Finally, personal accomplishment was lower among respondents with numerous overtime hours.

Including further predictors presented in the Methods section such as education, household structure, or the length of overall professional experience into the model did not improve the prediction (result not shown). Only a degree of activity from $90 \%$ to $100 \%$ (unstandardized coefficient $=$ $-1.26, t=-1.67$, and $P=0.096)$ and working in a local hospital (unstandardized coefficient $=1.70, t=1.91$, and $P=$ 0.057 ) had a borderline effect on the depersonalization score.

\section{Discussion}

Health professionals belong to the traditional occupational groups investigated by the research on burnout. Emotionally demanding tasks, high workload, a stressful environment, or conflicts and unfulfilled expectations when working with patients underpin the view that occupations such as nursing are inherently prone to burnout. Building on this view, research focused on professionals in specialities or settings which are perceived as highly stressful such as oncology, intensive care, or palliative care. Little, however, is known about nursing managers even though they can be presumed to face a very demanding job. Combining both nursing tasks and management tasks like motivation, organization, and conflict resolution may increase the risk of burnout. The present study examined the prevalence of burnout and its variations according to personal, work-related, and organizational characteristics among nursing managers in Western Switzerland.

The main findings of the study concern a low degree of burnout among nursing managers and a widely similar incidence of burnout on nursing and medical managers. Also, characteristics were most often significant predictors for emotional exhaustion, while most of them were not related to depersonalization and personal accomplishment. As regards the degree of burnout, only a small proportion of nursing managers (2.3\%) had a high emotional exhaustion, a high depersonalization, and a low personal accomplishment, that is, a high degree of burnout. Though no comparative data are available for nurses without a management function in Switzerland, the proportion of nursing managers is similar to those found for Swiss primary physicians (3.5\%; [27]) and medical managers in the present study (3.1\%). Compared with North American nursing managers [19], Swiss respondents were consistently less prone to burnout (mean scores of emotional exhaustion: 23.7 versus 16.9, depersonalization:
18.0 versus 5.4, and personal accomplishment: 22.5 versus 35.6). Similarly, a comparison with research on nurses without a manager function in other countries generally shows a similar (nurses in general hospitals [28]) or higher incidence of burnout than for the Swiss nursing managers (oncology nurses $[9,29,30])$. Overall, cross-national comparisons suggest that the rate of nurses with a low level of emotional exhaustion subscale according to the corresponding subscale of the MBI-HSS is particularly low in Switzerland (14.6\% according to [31] versus $16.9 \%$ in the present study). The lowest rate was found in The Netherlands where, according to another research, human service professionals including nurses showed slightly less favourable mean scores on the three subscales of the MBI-HSS to the present study [32].

There can be several reasons for the low incidence of burnout on nursing managers in Switzerland. Firstly, cultural and contextual differences may explain the higher rates of burnout in the North American manager sample, as nurses tend to have lower scores on burnout in Europe than in North America [32]. Secondly, low degrees of burnout among Europeans might not be specific to managers and reflect a cross-national difference in the prevalence of burnout [31]. Thirdly, in line with theories about coping and empowerment [23-25], managers may benefit from higher resources which are, for instance, related to education or job autonomy to help them face stressful situations than nurses with no management function. Unequal distribution of resources would therefore contribute to explaining differences in the incidence of burnout.

As already pointed out, the proportions of nursing managers and medical managers with a high degree of burnout are similar in the present study. Mean scores on the emotional exhaustion and the depersonalization subscales did not differ significantly, while personal accomplishment was only slightly lower among nursing managers. To our knowledge, research has not yet compared nursing and medical managers. Findings from studies about nurses and physicians do not consistently indicate which ones are more prone to burnout $[29,30]$. A possible explanation for the similarity of burnout between nurses and physicians in the present study may be due to the converging tasks and hierarchically comparable positions. For instance, subordination of nurses to physicians may be less accentuated in the case of managers and specific attributes of nurse and physician activities may play a minor role compared to the similar management tasks of both groups.

Prediction of burnout was contrasted as the personal and work-related characteristics were mainly related to emotional exhaustion. While job-related characteristics are classical predictors of burnout, they were only partly associated with burnout in the present study [30]. As an indicator of workload, overtime reduced the scores of personal accomplishment, but it was not related to the two other subscales. Irregular working hours and frequent conflicts within the team strongly accentuated the emotional exhaustion. Personal characteristics like sex, age, and managerial experience showed a moderate association with burnout. Scores were lower for younger age (emotional exhaustion) and longer experience (depersonalization), while depersonalization was 
more pronounced among women than men. Results for age and experience are widely consistent with previous research [33], while findings regarding sex are variable [34]. Increased emotional exhaustion was also related to discrepancies between personal and organizational values and between personal skills and job demands, thereby emphasizing the role of perceived work conditions. These results may be related to the homogeneity of the respondents due to their management function in the present study. It may be speculated that they encounter widely similar work constraints. Homogeneity could then result in less variations across the characteristics under study, especially for the dimensions of burnout related to the relationships with other persons (depersonalization) and to efficacy at work (personal accomplishment). Emotional exhaustion, however, varies across the characteristics, revealing a possible association with personality features [35].

The present study has some limitations. Firstly, as participants were contacted at their work place, those who were absent for a long period could possibly not be reached. Therefore, the study probably underestimates the proportion of health managers with a high degree of burnout, as they are likely to be on sick leave. Though this recruitment bias is common to most studies about burnout in organizational settings, findings should be considered to be conclusive for rather moderate ranges of burnout. Furthermore, the comparison of burnout between studies may be uncertain as the share of nonsurveyed professionals with high scores may vary across the settings investigated by the different studies. Secondly, findings should not be interpreted in a clinical sense as the self-reports obtained by the MBI-HSS are not diagnostics. In particular, the categorization of burnout based on the normative North American sample is merely a statistical one, as it classified the respondents on a distributional criterion (lower, middle, and upper third of the scores [15]). Categorization is thus arbitrary and depends on a specific sample which is ignoring, for instance, cultural differences between countries, and even slight shifts in the thresholds may lead to strong changes in burnout rates [32]. It should not be viewed as being intrinsically tied to burnout but rather as a common basis to draw comparisons across settings. Hence, the present study widely analysed the scores of burnout themselves in addition to its categorization. Thirdly, as participation in the study was on a voluntary basis and characteristics of nonparticipants could not be identified, some subgroups may be over- or underrepresented. Also, contextual characteristics such as cultural factors or specificities of the health system were not included in the analysis. Thus, generalizations should be made carefully, especially when using the results of the present study for cross-national comparisons.

\section{Conclusion}

Though nursing managers could be thought to be especially at risk due to their demanding job, they showed a rather low degree of burnout in the present study. Therefore, the issue of whether high stress settings lead to high burnout should be questioned further. Differences in resources including coping strategies between nurses with and without management function should be investigated.

\section{Conflict of Interests}

The authors declare that there is no conflict of interests regarding the publication of this paper.

\section{Acknowledgment}

The study was supported by the Swiss National Science Foundation, Grant 13DPD6_134764.

\section{References}

[1] H. J. Freudenberger, "Staff burnout," Journal of Social Issues, vol. 30, no. 1, pp. 159-165, 1974.

[2] H. J. Freudenberger and G. Richelson, Burnout: The High Cost of High Achievement, Doubleday, New York, NY, USA, 1980.

[3] B. M. Jennings, "Work stress and burnout among nurses: role of the work environment and working conditions," in Patient Safety and Quality: An Evidence-Based Handbook for Nurses, R. G. Hughes, Ed., vol. 2, pp. 137-158, Agency for Healthcare Research and Quality, Rockville, Md, USA, 2008.

[4] A. Pines, "Burnout: an existential perspective," in Professional Burnout: Recent Developments in Theory and Research, W. B. Schaufeli, C. Maslach, and T. Marek, Eds., pp. 33-51, Taylor and Francis, Philadelphia, Pa, USA, 1993.

[5] O. Huerta Melchor, Managing Change in OECD Governments: An Introductory Framework, 2008.

[6] E. R. Greenglass, R. J. Burke, and L. Fiksenbaum, "Workload and burnout in nurses," Journal of Community and Applied Social Psychology, vol. 11, no. 3, pp. 211-215, 2001.

[7] M. Alderson, E. Morin, J. Rhéaume, M. Saint-Jean, and F. Ouellet, "La réorganisation du travail infirmier en soins de longue durée: une nécessaire évaluation en termes d'impact sur le sens du travail et la santé mentale des infirmières," Santé mentale au Québec, vol. 30, no. 2, pp. 345-358, 2005.

[8] B. R. Norrish and T. G. Rundall, "Hospital restructuring and the work of registered nurses," Milbank Quarterly, vol. 79, no. 1, pp. 55-79, 2001.

[9] L. H. Aiken, S. P. Clarke, and D. M. Sloane, "Hospital staffing, organization, and quality of care: cross-national findings," Nursing Outlook, vol. 50, no. 5, pp. 187-194, 2002.

[10] M. Stanley, K. Blair, and P. Gauntlett Beare, Eds., Gerontological Nursing: Promoting Successful Aging with Older Adults, F.A. Davis, Philadelphia, Pa, USA, 2005.

[11] R. G. Evans, K. M. McGrail, S. G. Morgan, M. L. Barer, and C. Hertzman, "Apocalypse no: population aging and the future of health care systems," Canadian Journal on Aging, vol. 20, no. 1, pp. 160-191, 2001.

[12] V. Drury, M. Craigie, K. Francis, S. Aoun, and D. G. Hegney, "Compassion satisfaction, compassion fatigue, anxiety, depression and stress in registered nurses in Australia: phase 2 results," Journal of Nursing Management, 2013.

[13] L. J. Ducharme, H. K. Knudsen, and P. M. Roman, "Emotional exhaustion and turnover intention in human service occupations: the protective role of coworker support," Sociological Spectrum, vol. 28, no. 1, pp. 81-104, 2008. 
[14] M. M. Davey, G. Cummings, C. V. Newburn-Cook, and E. A. Lo, "Predictors of nurse absenteeism in hospitals: a systematic review," Journal of Nursing Management, vol. 17, no. 3, pp. 312330, 2009.

[15] C. Maslach, S. E. Jackson, and M. P. Leiter, Maslach Burnout Inventory Manual, Consulting Psychologists Press, Palo Alto, Calif, USA, 3rd edition, 1996.

[16] R. G. Hughes, Ed., Patient Safety and Quality: An EvidenceBased handbook for Nurses, Agency for Healthcare Research and Quality, Rockville, Md, USA, 2008.

[17] E. R. Greenglass and R. J. Burke, "Hospital restructuring and burnout," Journal of Health and Human Services Administration, vol. 25, no. 1, pp. 89-114, 2004.

[18] M. Ledgister, "The nursing shortage crisis: a familiar problem dressed in new clothes," International Journal of Health Care Quality Assurance, vol. 16, no. 1, pp. 14-22, 2003.

[19] V. Lee and M. C. Henderson, "Occupational stress and organizational commitment in nurse administrators," Journal of Nursing Administration, vol. 26, no. 5, pp. 21-28, 1996.

[20] S. Wang, Y. Liu, and L. Wang, "Nurse burnout: personal and environmental factors as predictors," International Journal of Nursing Practice, 2013

[21] M. M. Malliarou, E. C. Moustaka, and T. C. Konstantinidis, "Burnout of nursing personnel in a regional university hospital," Health Sciences Journal, vol. 2, pp. 140-152, 2008.

[22] D. Edwards, P. Burnard, D. Coyle, A. Fothergill, and B. Hannigan, "Stress and burnout in community mental health nursing: a review of the literature," Journal of Psychiatric and Mental Health Nursing, vol. 7, no. 1, pp. 7-14, 2000.

[23] Y. Chang and H. J. Chan, "Optimism and proactive coping in relation to burnout among nurses," Journal of Nursing Management, 2013.

[24] H. K. Spence Laschinger, S. Gilbert, L. M. Smith, and K. Leslie, "Towards a comprehensive theory of nurse/patient empowerment: applying Kanter's empowerment theory to patient care," Journal of Nursing Management, vol. 18, no. 1, pp. 4-13, 2010.

[25] J. I. J. Wagner, G. Cummings, D. L. Smith, J. Olson, L. Anderson, and S. Warren, "The relationship between structural empowerment and psychological empowerment for nurses: a systematic review," Journal of Nursing Management, vol. 18, no. 4, pp. 448-462, 2010.

[26] SPSS, SPSS Base 19. 0 User's Guide, SPSS, Chicago, Ill, USA, 2010.

[27] C. Goehring, M. B. Gallacchi, B. Künzi, and P. Bovier, "Psychosocial and professional characteristics of burnout in Swiss primary care practitioners: a cross-sectional survey," Swiss Medical Weekly, vol. 135, no. 7-8, pp. 101-108, 2005.

[28] E. Grau-Alberola, P. R. Gil-Monte, J. A. García-Juesas, and H. Figueiredo-Ferraz, "Incidence of burnout in Spanish nursing professionals: a longitudinal study," International Journal of Nursing Studies, vol. 47, no. 8, pp. 1013-1020, 2010.

[29] C. Bressi, S. Manenti, M. Porcellana et al., "Haemato-oncology and burnout: an Italian survey," British Journal of Cancer, vol. 98, no. 6, pp. 1046-1052, 2008.

[30] J. Adriaenssens, V. De Grucht, and S. Maes, "Causes and consequences of occupational stress in emergency nurses, a longitudinal study," Journal of Nursing Management, 2013.

[31] L. H. Aiken, W. Sermeus, K. Van Den Heede et al., "Patient safety, satisfaction, and quality of hospital care: cross sectional surveys of nurses and patients in 12 countries in Europe and the United States," British Medical Journal, vol. 344, no. 7851, Article ID e1717, 2012.
[32] W. B. Schaufeli and D. Van Dierendonck, "A cautionary note about the cross-national and clinical validity of cut-off points for the Maslach Burnout Inventory," Psychological Reports, vol. 76, no. 3, pp. 1083-1090, 1995.

[33] E. W. Brewer and L. Shapard, "A meta-analysis of the relationship between age or years of experience," Human Resource Development Review, vol. 3, pp. 102-123, 2004.

[34] S. O. Adebayo and J. C. Osagu, "Gender differences in burnout among health workers in the Ekiti State University Teaching Hospital Ado-Ekiti," International Journal of Social and Behavioural Sciences, vol. 1, no. 6, pp. 112-131, 2013.

[35] M. Shimizutani, Y. Odagiri, Y. Ohya et al., "Relationship of nurse burnout with personality characteristics and coping behaviors," Industrial Health, vol. 46, no. 4, pp. 326-335, 2008. 


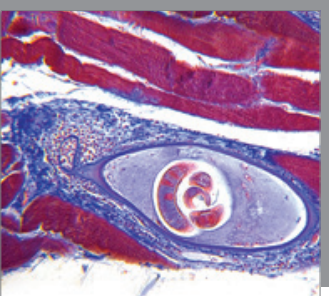

Gastroenterology

Research and Practice
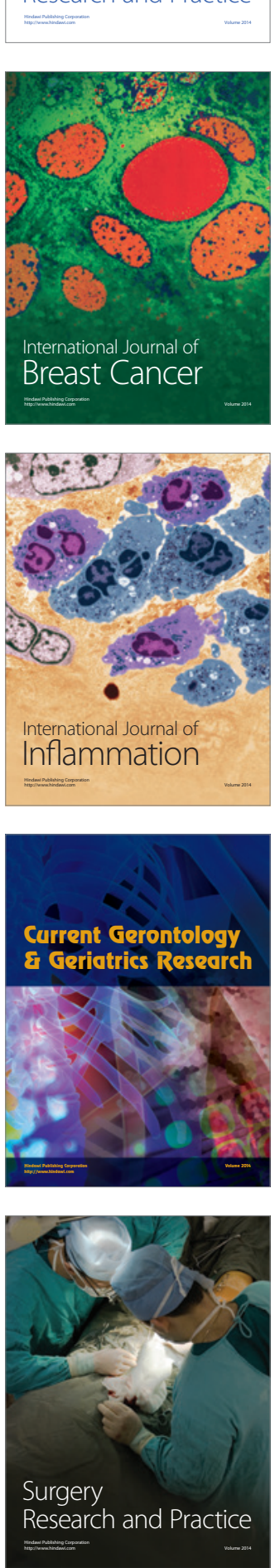

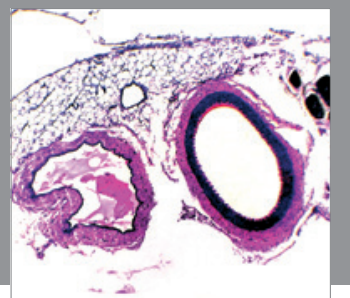

International Journal of Hypertension
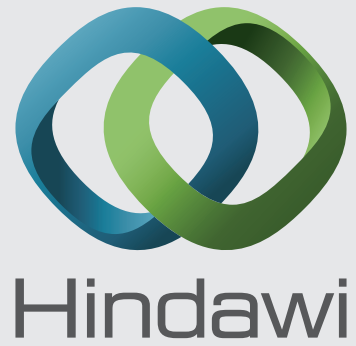

Submit your manuscripts at http://www.hindawi.com
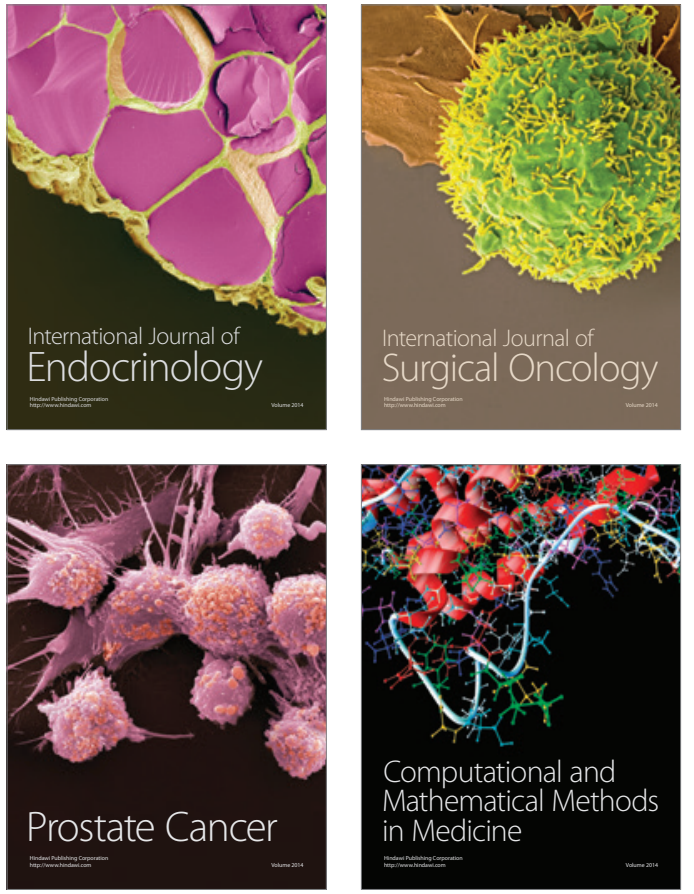
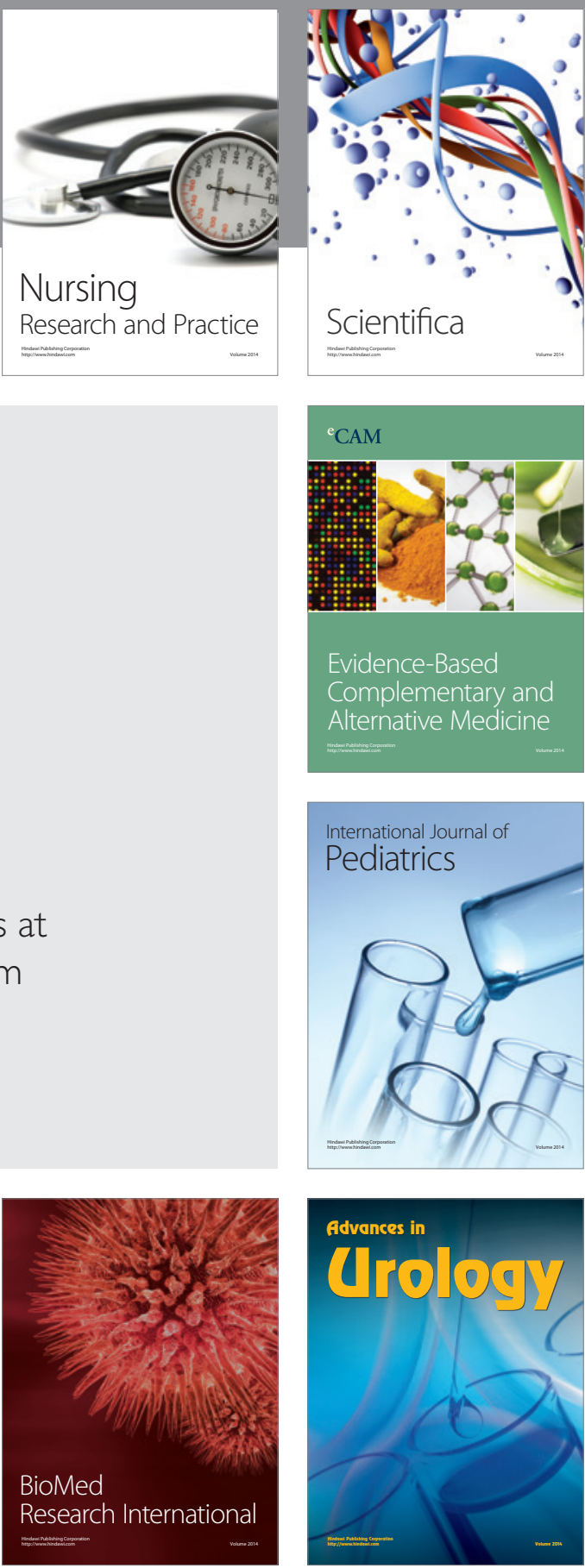

Nursing

Research and Practice

Scientifica

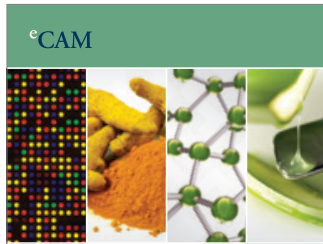

Evidence-Based

Complementary and Alternative Medicine
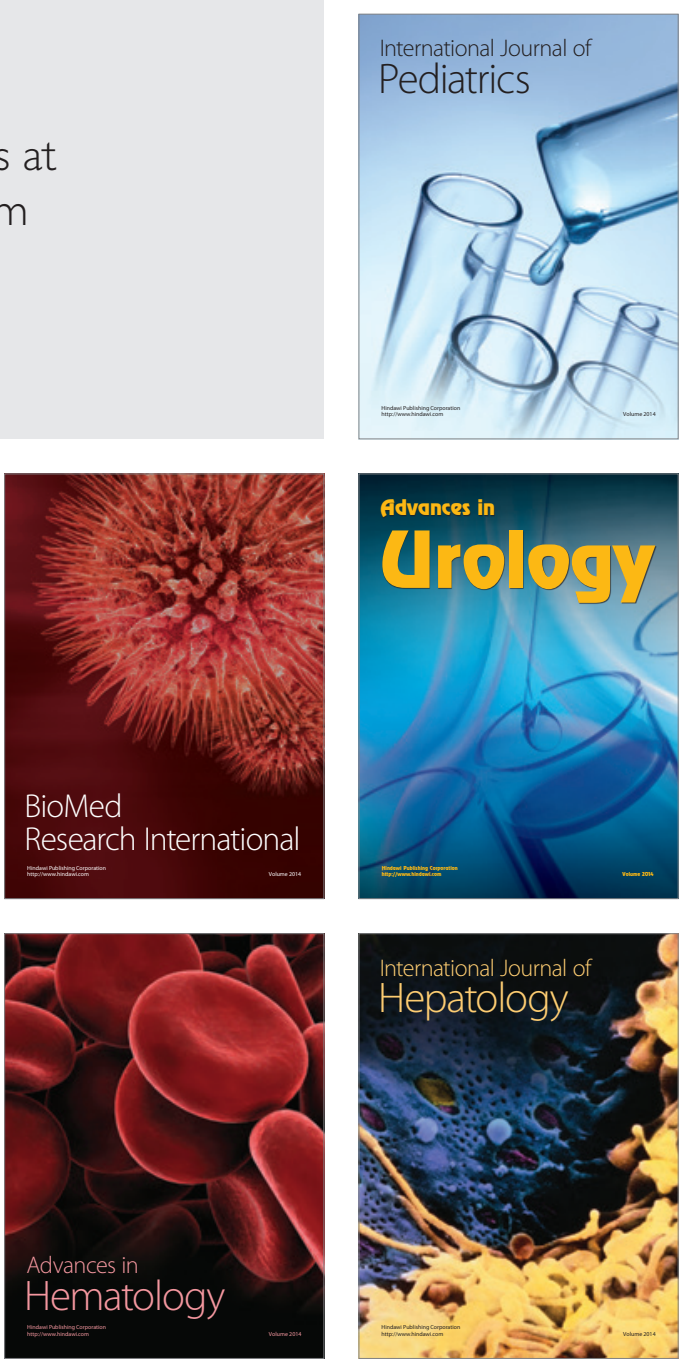